\title{
Longer family medicine residency being considered for Canada
}

\author{
n Cite as: CMAJ 2018 October 15;190:E1235-6. doi: 10.1503/cmaj.109-5653
}

Posted on cmajnews.com on Sept. 25, 2018.

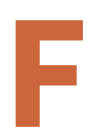

or many years, medical leaders have argued that Canada's two-year family medicine residency is too short. Now, the College of Family Physicians of Canada (CFPC) is embarking on an ambitious evaluation of the family medicine residency. Over the next 18 months to two years, the CFPC will consult residency program leaders, government representatives and regulatory authorities.

"We're doing an extensive review of our training requirements," said Nancy Fowler, executive director of academic family medicine at the CFPC. "Once that's completed, that could prompt the question of 'Okay, is this possible in the time that we have in residency?"”

The impetus for the re-evaluation was the CFPC's release last spring of the Family Medicine Professional Profile. The profile describes family physicians as providing both acute and chronic medical care, in addition to "working across care settings," including hospitals and homes, while also contributing to health system leadership, advocacy and research.

"Health care has evolved quite a bit, with the growth of home-based care, collaborative care and team leadership. This evolution demands a relook to be sure that people are learning the right stuff in the right context," said Fowler.

Dr. Sandy Buchman, president-elect of the Canadian Medical Association, thinks new family medicine physicians aren't prepared to provide the outside-theoffice care that many patients need. Six years ago, he wrote an article calling for the extension of family medicine residencies because he was seeing many family doctors restrict their practices to office settings after residency, or doing a third year of training in palliative care, emer-

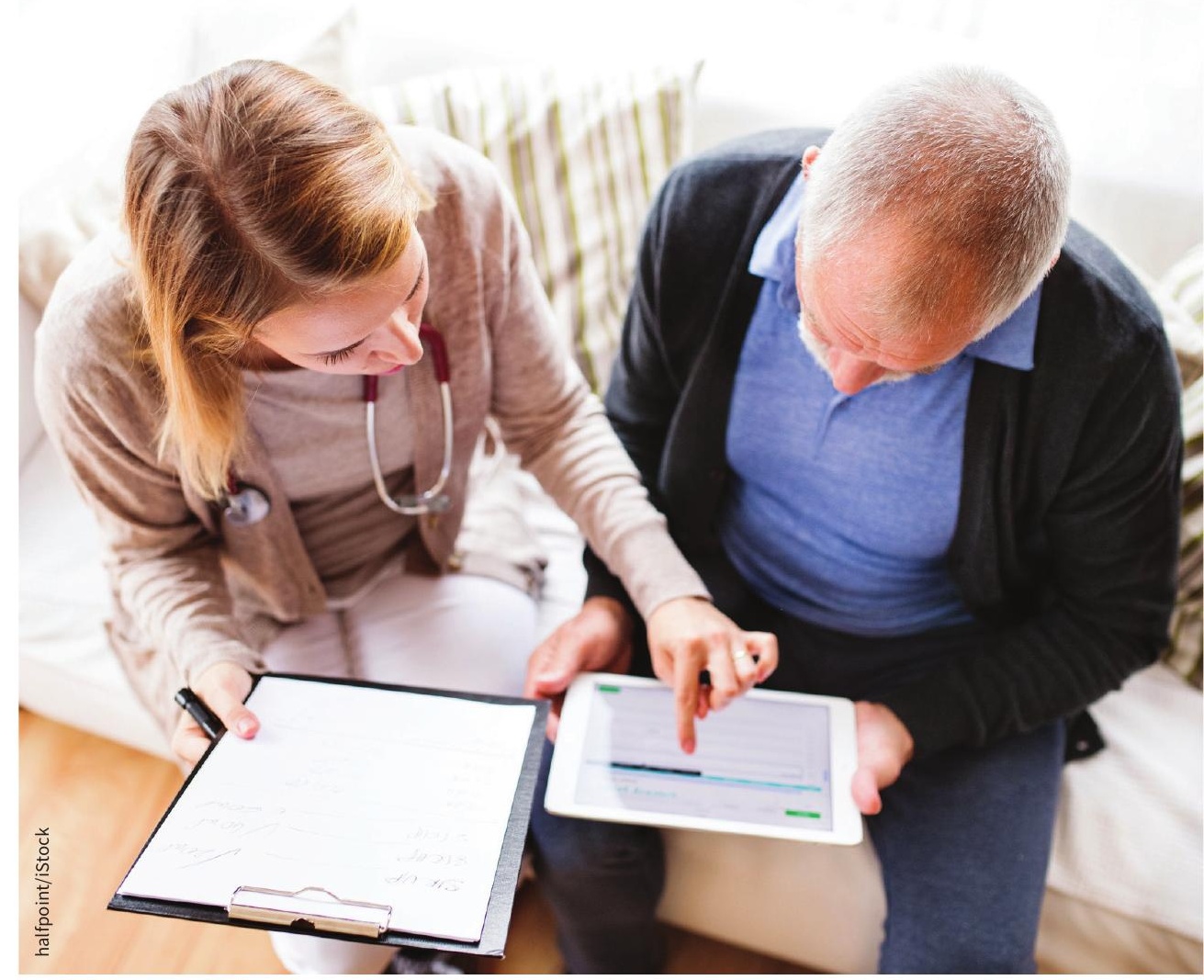

Increased demand for home-based care may require additional training for family medicine residents.

gency medicine or another specialization.

He's worried that family doctors aren't being trained to provide home care, which is in high demand because of a growing cohort of aging seniors who don't want to go to emergency departments. "Sometimes [young family doctors] have never been out on a home visit, or have only been on one," he said. And because the tests young doctors are typically taught to order aren't available in the home environment, "a lot more is dependent on professional judgment ... that competency takes time." Family medicine, in general, is "more broad and more complex, and to really get it all into two years is astounding to me," said Buchman.

But according to Dr. Catherine Cervin, associate dean of postgraduate education at the Northern Ontario School of Medicine, the length of residency is less important than its quality and location. "It's about what residents are learning, where they're learning it, and how their trajectory of competence is developing," she said. Cervin argues that more training programs need to be developed in areas where doctors are most needed, including Indigenous and rural communities. 
Given that family physicians will need different skills, depending on the needs of their communities, Cervin thinks that rather than extending residency, emphasis should be put on how to enhance professional development programs for family physicians already in practice. A family physician can start with the basics of care, but may need to develop surgical skills, or more advanced skills in obstetrics or mental health care, especially as older physicians who provide such specialized care retire.

"Those enhanced skills do not need to happen immediately after residency training," said Cervin. "There could be a sys- tem to develop those skills while doctors are practising."

Current professional development programming for family doctors isn't sufficient for learning major new areas, according to Fowler, who hopes that more intensive, part-time professional development options will become available in the future. "Continuing professional development currently just doesn't allow for that ongoing, more intensive, skill development, and you're never going to be able to frontload all of that into residency training because there is such a diversity of skills that people end up needing for their local context."
Buchman thinks that both a third year of residency and a better system for skills development for practising physicians is required. "Why did so many Western countries go with four-, five- or six-year family medicine residencies?" he asked. He pointed to Israel, the United Kingdom and France, all of which have "excellent primary care systems" that outperform Canada on a number of measures. The UK and France have family residency programs of three years and Israel has a fouryear program. "What do they know that we don't know?"

Wendy Glauser, Toronto, Ont. 